\title{
Assessment of Multiple Sclerosis Awareness and Knowledge among the Community of Jeddah, Saudi Arabia
}

\author{
Eyas K. Farran ${ }^{1}$ Dania S. Waggas ${ }^{1}$ Tala A. Alkhunani ${ }^{2}$ Safwan A. Almuwallad ${ }^{3}$ Rola A. Aljohani ${ }^{4}$ \\ ${ }^{1}$ Department of Medicine, Fakeeh College for Medical Sciences, \\ Jeddah, KSA, Saudi Arabia \\ ${ }^{2}$ College of Medicine, King Saud bin Abdulaziz University for Health \\ Sciences, Jeddah, KSA, Saudi Arabia \\ Address for correspondence Eyas K. Farran, Department of Medicine, \\ Fakeeh College for Medical Sciences, Abdul Wahab Naib Al Haram, \\ Al-Hamra'a, Jeddah 23323, Saudi Arabia \\ (e-mail: eyas.khalid.f@gmail.com).
}

${ }^{3}$ College of Medicine, Umm al-Qura University, Mecca, KSA, Saudi Arabia

${ }^{4}$ Department of Medicine, ibn Sina National College, Jeddah, KSA,

Saudi Arabia

J Neurosci Rural Pract 2021;12:733-738.

\section{Introduction}

Multiple sclerosis (MS) is a long-lasting disease of the central nervous system (CNS). ${ }^{1,2}$ It is considered to be an
Objective Multiple sclerosis (MS) is a degenerative disease of the central nervous system that can lead to lifelong disabilities. There is a significant increase in the global incidence of the disease. In Saudi Arabia (SA), the western region has the greatest number of MS cases. However, there is a lack of studies and research to assess public knowledge in the region. Thus, we aim to assess the public's knowledge of MS in Jeddah, SA.

Methodology We conducted a cross-sectional study surveying 468 participants from the general population of Jeddah. A validated MS knowledge questionnaire (MSKQ-25) was used.

Results Most participants were female 347 (74.1\%) with a mean age of $35.73 \pm 14.71$ standard deviation (SD). MS was found in 14 (3\%) of the participants. The average score of the (MSKQ) was $7.42 \mathrm{SD} \pm 4.568$ versus the average score of people with MS with a mean of $13.92 \mathrm{SD} \pm 3.33$ and a $p$ value $>0.001$. No significant variation was found in knowledge between gender and age groups, but there was a significant correlation between the educational level and the knowledge level.

Conclusion The mean knowledge score was below average, which indicates poor knowledge of MS. Since the western region has the highest number of MS cases in SA, the level of understanding needs to increase. This can be improved by conducting educational programs using various types of media. published online September 16, 2021
DOI https://doi.org/ $10.1055 / \mathrm{s}-0041-1734009$. ISSN 0976-3147. autoimmune disorder characterized by CNS inflammation, demyelination, axonal injury, and axonal loss, yet the exact antigen of the immunological response is unclear. $^{3}$ It is a progressive disease that affects individuals, leading
(C) 2021. Association for Helping Neurosurgical Sick People. All rights reserved.

This is an open access article published by Thieme under the terms of the Creative Commons Attribution-NonDerivative-NonCommercial-License, permitting copying and reproduction so long as the original work is given appropriate credit. Contents may not be used for commercial purposes, or adapted, remixed, transformed or built upon. (https://creativecommons.org/ licenses/by-nc-nd/4.0/)

Thieme Medical and Scientific Publishers Pvt. Ltd., A-12, 2nd Floor, Sector 2, Noida-201301 UP, India 
to lifelong disabilities and negatively influencing productivity and quality of life. ${ }^{4}$

The exact cause of the disease is unknown. However, the epidemiological data shows that both environmental and genetic factors play a vital role in the progress of MS; the prevalence of MS is not evenly distributed across the globe ${ }^{5-7}$ Therefore, MS treatments are divided into two categories: drugs that control the disease progress and the other medications to manage the clinical symptoms. ${ }^{8}$

The prevalence of MS has increased globally in recent years, according to the Atlas of MS by the World Health Organization (WHO) in 2008. The approximate prevalence of MS worldwide is 30 per 100,000 , and the number of diagnosed cases in the same year is 2.1 million. $^{9}$ In 2013, the global median prevalence increased to 33 per 100,000 . The number of diagnosed cases increased to 2.3 million cases. ${ }^{10}$

Regarding the risk factor for the disease, a case-control study done in Saudi Arabia (SA) showed that sun exposure and healthy eating were associated with decreased risk of the disease, while eating fast food increased the risk of the disease. ${ }^{11}$ Moreover, the increased recurrence risk within families indicates a role in the genetic predisposition of MS. ${ }^{12}$

A study in 2016 among 715 individuals from Taif city, SA, reported poor knowledge regarding MS in 74\% of the cohort; $26 \%$ of the participants had adequate knowledge. ${ }^{13}$ Another study in SA's capital city not only revealed poor knowledge regarding the nature of the disease but also reported that the commonly used source of information was learning from people inside their circle. ${ }^{1}$ In Turkey, a study revealed that knowledge regarding MS was favorable among the patients themselves and their relatives, but there was poor understanding of the disease among the community. ${ }^{14}$

However, several studies were published concerning a specific population. In 2017, a study was done to assess the knowledge of Iranian pregnant women; the knowledge that they possessed regarding MS was moderate. ${ }^{15}$ MS patients in SA have less knowledge of both the types and treatment of the disease; however, they possess more knowledge about the pathophysiology of the disease. ${ }^{16}$

Despite increasing research and clinical attention, MS is a major health issue due to a lack of knowledge and understanding regarding the nature of the disease. There is no effective curable management of patients with MS; knowledge and awareness are important and can decrease the uncertainty and fill the gap between the patient and the public. MS is more common in the western region of SA, and we thus aimed to evaluate and assess Jeddah resident's knowledge regarding the different aspects of MS. ${ }^{17}$

\section{Methodology}

\section{Study Design, Sample Size, and Criteria}

This was a descriptive cross-sectional study conducted among the public in Jeddah, SA, during June and July of 2020. The study was approved by the institutional review board of Dr. Soliman Fakeeh Hospital (DSFH). We ensured the privacy and confidentiality of the participants' answers. Only the authors have access to the data. The estimated sample size that represents Jeddah citizens was 385 , calculated using the Raosoft Sample size calculator. ${ }^{18}$ We excluded any individuals who were below 18 years and all health care workers.

\section{Tools and Measurement}

We used the MS knowledge questionnaire (MSKQ-25). Its validity was tested in a previous study, and the internal consistency (Kuder-Richardson-20 Eq. 0.76) and content validity were good. ${ }^{19}$ The questionnaire contains 25 items divided into two major parts: sociodemographic data and the actual (MSKQ-25) with 25 items to assess the knowledge regarding MS. Each item consists of MCQ with three to five possible answers. The correct answer was given one point. Thus, the minimum score is zero, and the highest possible score by completing this survey is 25 .

\section{Pilot Study}

The MSKQ-25 is available in English, and an Arabic translation was done first for our population. The first step was a forward translation. In this step, two bilingual translators whose native language was Arabic translated the English version of the MSKQ-25 questionnaire into Arabic. The second step was a backward translation of the Arabic version of the questionnaire by two translators whose native language was English and Arabic was their second language. As the third step, the two Arabic translations were combined into a single translation. The fourth step was reviewing the (MSKQ-25) by a translator who is unaware of the concept of the questionnaire and had no medical background to ensure it is accessible to public Arabic readers. In the fifth and last step, 45 participants were asked to complete the Arabic version of the (MSKQ-25) questionnaire and provide us with feedback.

\section{Data Processing and Analysis}

Data were collected via an electronic survey made by Google forms and distributed on social media platforms. The aim of the study and consent of voluntary participation was on the landing page of the questionnaire. Data was exported to Microsoft Excel 2019. Analysis of the raw data used IBM Statistical Package for the Social Sciences (SPSS) software version 25. The following statistical test was performed. Frequencies and percentages were used for the qualitative variables, and the measure of central tendency was used for the quantitative variables. The Chi-square test and the Mann-Whitney $U$ test were used in the analysis of variance. Confidence intervals were $95 \% \mathrm{CI}$ with a $5 \%$ margin of error; all $p$ values $<0.05$ were considered statistically significant.

\section{Results}

We received 516 responses that met our inclusion criteria, but only 468 responses were included in the final analysis after removing 48 participants due to missing data. There were 121 (25.9\%) males and 347 (74.1\%) females. The mean age was $35.73 \pm 14.71$ years. Nearly half of the sample were married (50\%), and 14 (3\%) of the participants were diagnosed with MS. The average score on the MSKQ was 7.42 
standard deviation $(\mathrm{SD}) \pm 4.568$. The minimum score was 1 (7.3\%), and the maximum score was $19(0.4 \%)$ out of 25 .

We found a marked increase in the average knowledge score in MS diagnosed group compared with the public community, with a mean of $13.92 \mathrm{SD} \pm 3.33$ and $p$ value $>0.001$ ( - Table 1).

Regarding the MSKQ, we divided the answers into three groups according to the score to make it easier for comparison. The first category included the people who scored less than 50\%. There were 385 (82.3\%) such participants. The second category included people who scored between $50 \%$ and less than 70\%; they were 76 (16.2\%). The last group comprised 7 (1.5\%) participants who had scored $70 \%$ and above. The most correctly answered questions were Q1 and Q6. Q3, Q16, and Q19 were least likely to be correctly answered.
Each item of the questionnaire was given a label with the concept of the question and arranged, according to the aim of the question. Regarding the nature of the disease, most people 355 (75.9\%) report that MS is a disease affecting the CNS, while 182 (38.9\%) of the total participants recognize that the CNS is composed of the brain, spinal cord, and optic nerves. Only 103 (22.0\%) knew that MS is not associated with decrease in lifespan, the majority of respondents $(n=417$; 89.1\%) knew that MS is not contagious, and 173 (37.0\%) answered that the disease affects the immune system. Here, $132(28.2 \%)$ responded that MS injures both the axon and the myelin, and 163 (34.8\%) knew that myelin facilitates and speeds up the transition of the nerve impulse.

When we asked about the prevalence and predisposing factors, only 23 (4.9\%) recognized the prevalence of the

Table 1 Knowledge level regarding the demographic data

\begin{tabular}{|c|c|c|c|c|c|}
\hline Variable & $n(\%)$ & MSKQ score $<50 \%$ & $\begin{array}{l}\text { MSKQ Score } \\
50 \% \text { to } \leq 70 \%\end{array}$ & $\begin{array}{l}\text { MSKQ } \\
\text { score >70\% }\end{array}$ & p-Value \\
\hline & & $n=385(\%)$ & $n=76(\%)$ & $n=7(\%)$ & \\
\hline \multicolumn{6}{|l|}{ Gender } \\
\hline Male & $121(25.9 \%)$ & $97(25.2 \%)$ & $22(28.9 \%)$ & $2(28.6 \%)$ & \\
\hline Female & $347(74.1 \%)$ & $288(74.8 \%)$ & $54(71.1 \%)$ & $5(71.4 \%)$ & $<0.05$ \\
\hline \multicolumn{6}{|l|}{ Educational level } \\
\hline Middle school & $3(0.6 \%)$ & - & $3(3.9 \%)$ & - & \\
\hline High school & $117(25.0 \%)$ & $100(26.0 \%)$ & $16(21.1 \%)$ & $1(14.3 \%)$ & \\
\hline Bachelors & $318(67.9 \%)$ & 262 (68.1\%) & $51(67.1 \%)$ & $5(71.4 \%)$ & \\
\hline Academic & $30(6.4 \%)$ & $23(6.0 \%)$ & $6(7.9 \%)$ & $1(14.3 \%)$ & $<0.05$ \\
\hline \multicolumn{6}{|l|}{ Age group } \\
\hline $18-24$ & 148 (31.6\%) & 125 (32.5\%) & $21(27.6 \%)$ & 2 (28.6\%) & \\
\hline $25-34$ & $120(25.6 \%)$ & $89(23.1 \%)$ & $29(38.2 \%)$ & 2 (28.6\%) & \\
\hline $35-44$ & $23(4.9 \%)$ & $20(5.2 \%)$ & $2(2.6 \%)$ & $1(14.3 \%)$ & \\
\hline $45-54$ & 89 (19\%) & 75 (19.5\%) & $13(17.1 \%)$ & $1(14.3 \%)$ & \\
\hline $55-64$ & $81(17.3 \%)$ & 69 (17.9\%) & $11(14.5 \%)$ & $1(14.3 \%)$ & \\
\hline $65+$ & 7 (1.5\%) & 7 (1.8\%) & - & - & $<0.05$ \\
\hline \multicolumn{6}{|l|}{ History of MS } \\
\hline Yes & $14(3 \%)$ & $5(1.3 \%)$ & $6(7.9 \%)$ & $3(42.9 \%)$ & \\
\hline No & 454 (97\%) & 380 (98.7\%) & 70 (92.1\%) & $4(57.1 \%)$ & $<0.05$ \\
\hline \multicolumn{6}{|l|}{ Marital status } \\
\hline Married & $234(50 \%)$ & $190(49.4 \%)$ & 39 (51.3\%) & $5(71.4 \%)$ & \\
\hline Single & $212(45.3 \%)$ & 177 (46\%) & $33(43.4 \%)$ & $2(28.6 \%)$ & \\
\hline Divorced & $22(4.7 \%)$ & $18(4.7 \%)$ & $4(5.3 \%)$ & - & $<0.05$ \\
\hline \multicolumn{6}{|l|}{ Monthly income } \\
\hline Less than 5000 & 209 (44.7\%) & $173(44.9 \%)$ & $33(43.4 \%)$ & $3(42.9 \%)$ & \\
\hline $5000-10000$ & $88(18.8 \%)$ & $71(18.4 \%)$ & $16(21.1 \%)$ & $1(14.3 \%)$ & \\
\hline $10000-15000$ & 93 (19.9\%) & 76 (19.7\%) & $16(21.1 \%)$ & $1(14.3 \%)$ & \\
\hline $15000-20000$ & $52(11.1 \%)$ & $43(11.2 \%)$ & $9(11.8 \%)$ & - & \\
\hline More than 21000 & 26 (5.6\%) & $22(5.7 \%)$ & $2(2.6 \%)$ & $2(28.6 \%)$ & $<0.05$ \\
\hline
\end{tabular}

Abbreviations: (\%), percentage of participants; MS, multiple sclerosis; $n$, number of subjects. 
Table 2 Distribution of the correct response

\begin{tabular}{|c|c|c|c|c|c|c|c|}
\hline \#Q & & $\begin{array}{l}\text { MSKQ } \\
\text { score }<50 \%\end{array}$ & $\begin{array}{l}\text { MSKQ Score } \\
50 \% \text { to } \leq 70 \%\end{array}$ & $\begin{array}{l}\text { MSKQ } \\
\text { score }>70 \%\end{array}$ & $\begin{array}{l}\text { Correct } \\
\text { answers }\end{array}$ & \multirow[t]{2}{*}{$p$-Value } & \multirow{2}{*}{$\begin{array}{l}\text { Level of } \\
\text { awareness } \\
\text { and knowledge }\end{array}$} \\
\hline & & $n=385$ & $n=76$ & $n=7$ & $n=468$ & & \\
\hline \multicolumn{8}{|c|}{ Nature of the disease } \\
\hline 1 & $\begin{array}{l}\text { Organs involved in } \\
\text { MS }\end{array}$ & 279 (72.5\%) & $70(92.1 \%)$ & $6(85.7 \%)$ & $355(75.9 \%)$ & $<0.05$ & High \\
\hline 2 & CNS composition & 137 (35.6\%) & $40(52.6 \%)$ & $5(71.4 \%)$ & 182 (38.9\%) & $<0.05$ & Low \\
\hline 4 & $\begin{array}{l}\text { Impact of MS on life } \\
\text { expectancy }\end{array}$ & 65 (16.9\%) & $34(44.7 \%)$ & $4(57.1 \%)$ & $103(22 \%)$ & $<0.05$ & Low \\
\hline 5 & $\begin{array}{l}\text { MS as immune } \\
\text { disease }\end{array}$ & $114(29.6 \%)$ & $52(68.4 \%)$ & $7(100 \%)$ & $173(37 \%)$ & $<0.05$ & Low \\
\hline 6 & $\begin{array}{l}\text { MS as a contagious } \\
\text { disease }\end{array}$ & $335(87 \%)$ & 75 (98.7\%) & $7(100 \%)$ & 417 (89.1\%) & $<0.05$ & High \\
\hline 10 & $\begin{array}{l}\text { Myelin/axon } \\
\text { damage }\end{array}$ & $83(21.6 \%)$ & $46(60.5 \%)$ & $3(42.9 \%)$ & $132(28.2 \%)$ & $<0.05$ & Low \\
\hline 13 & Myelin function & 91 (23.6\%) & 65 (85.5\%) & $7(100 \%)$ & $163(34.8 \%)$ & $<0.05$ & Low \\
\hline \multicolumn{8}{|c|}{ Prevalence and predisposing factors } \\
\hline 3 & $\begin{array}{l}\text { Prevalence of MS in } \\
\text { Saudi Arabia }\end{array}$ & $6(1.6 \%)$ & $15(19.7 \%)$ & $2(28.6 \%)$ & $23(4.9 \%)$ & $<0.05$ & Low \\
\hline 11 & Age of onset & $117(30.4 \%)$ & $54(71.1 \%)$ & $7(100 \%)$ & $178(38 \%)$ & $<0.05$ & Low \\
\hline 12 & $\begin{array}{l}\text { Ratio of sex in MS } \\
\text { prevalence }\end{array}$ & $32(8.3 \%)$ & $32(42.1 \%)$ & 7 (100\%) & $71(15.2 \%)$ & $<0.05$ & Low \\
\hline 23 & $\begin{array}{l}\text { Pregnancy impact } \\
\text { on MS }\end{array}$ & 67 (17.4\%) & $29(38.2 \%)$ & $3(42.9 \%)$ & 99 (21.2\%) & $<0.05$ & Low \\
\hline \multicolumn{8}{|c|}{ Causation and genetic factor } \\
\hline 7 & MS etiology & $131(34 \%)$ & 55 (72.4\%) & $7(100 \%)$ & $193(41.2 \%)$ & $<0.05$ & Low \\
\hline 8 & $\begin{array}{l}\text { Transmission of MS } \\
\text { to offspring }\end{array}$ & $61(15.8 \%)$ & $32(42.1 \%)$ & $4(57.1 \%)$ & $97(20.7 \%)$ & $<0.05$ & Low \\
\hline 9 & $\begin{array}{l}\text { Transmission of MS } \\
\text { to other family } \\
\text { member }\end{array}$ & 44 (11.4\%) & $32(42.1 \%)$ & $6(85.7 \%)$ & $82(17.5 \%)$ & $<0.05$ & Low \\
\hline \multicolumn{8}{|c|}{ Diagnostic method and procedure } \\
\hline 14 & $\begin{array}{l}\text { Used tests to diag- } \\
\text { nose MS }\end{array}$ & $46(11.9 \%)$ & $34(44.7 \%)$ & $3(42.9 \%)$ & $83(17.7 \%)$ & $<0.05$ & Low \\
\hline 15 & $\begin{array}{l}\text { MRI role in MS } \\
\text { diagnosis }\end{array}$ & $137(35.6 \%)$ & 69 (90.8\%) & $7(100 \%)$ & $213(45.5 \%)$ & n.s & Moderate \\
\hline 16 & $\begin{array}{l}\text { Gadolinium injec- } \\
\text { tions' role during } \\
\text { MRI }\end{array}$ & $17(4.4 \%)$ & $16(21.1 \%)$ & - & $33(7.1 \%)$ & $<0.05$ & Low \\
\hline 17 & $\begin{array}{l}\text { MRI role on disease } \\
\text { follow-up }\end{array}$ & $125(32.5 \%)$ & $67(88.2 \%)$ & $7(100 \%)$ & $199(42.5 \%)$ & $<0.05$ & Low \\
\hline 18 & $\begin{array}{l}\text { Role of lumbar } \\
\text { puncture }\end{array}$ & $84(21.8 \%)$ & 60 (78.9\%) & $6(85.7 \%)$ & $150(32.1 \%)$ & $<0.05$ & Low \\
\hline 19 & $\begin{array}{l}\text { Frequency of lum- } \\
\text { bar puncture }\end{array}$ & $9(2.3 \%)$ & 10 (13.2\%) & $5(71.4 \%)$ & $24(5.15 \%)$ & $<0.05$ & Low \\
\hline 20 & $\begin{array}{l}\text { Definite diagnosis } \\
\text { of MS }\end{array}$ & 76 (19.7\%\%) & $42(55.3 \%)$ & $7(100 \%)$ & $125(26.7 \%)$ & $<0.05$ & Low \\
\hline \multicolumn{8}{|c|}{ Types and treatment } \\
\hline 21 & $\begin{array}{l}\text { Definition of remit- } \\
\text { tent MS }\end{array}$ & $63(16.4 \%)$ & $43(56.6 \%)$ & $6(85.7 \%)$ & $112(23.9 \%)$ & $<0.05$ & Low \\
\hline 22 & Benign MS & $56(14.5 \%)$ & $44(57.9 \%)$ & $5(71.4 \%)$ & 105 (22.4\%) & $<0.05$ & Low \\
\hline
\end{tabular}


Table 2 (Continued)

\begin{tabular}{|c|c|c|c|c|c|c|c|}
\hline \#Q & & $\begin{array}{l}\text { MSKQ } \\
\text { score < 50\% }\end{array}$ & $\begin{array}{l}\text { MSKQ Score } \\
50 \% \text { to } \leq 70 \%\end{array}$ & $\begin{array}{l}\text { MSKQ } \\
\text { score > 70\% }\end{array}$ & $\begin{array}{l}\text { Correct } \\
\text { answers }\end{array}$ & \multirow[t]{2}{*}{$p$-Value } & \multirow{2}{*}{$\begin{array}{l}\text { Level of } \\
\text { awareness } \\
\text { and knowledge }\end{array}$} \\
\hline & & $n=385$ & $n=76$ & $n=7$ & $n=468$ & & \\
\hline 24 & Curative treatment & $124(32.2 \%)$ & $61(80.3 \%)$ & $6(85.7 \%)$ & 191 (40.8\%) & $<0.05$ & Low \\
\hline 25 & $\begin{array}{l}\text { Types of MS disease } \\
\text { targeted by current } \\
\text { therapies }\end{array}$ & $8(2.1 \%)$ & $10(13.2 \%)$ & $1(14.3 \%)$ & $19(4.1 \%)$ & $<0.05$ & Low \\
\hline
\end{tabular}

Abbreviations: \#Q, question number; \%, percentage of participants; MS, multiple sclerosis; MSKQ, multiple sclerosis knowledge questionnaire; n.s, not statistically significant; $n$, number of participants.

disease in SA; 178 (38.0\%) knew the most affected age, while $71(15.2 \%)$ correctly answered that women are at higher risk of getting MS. Furthermore, 99 (21.2\%) agreed that being pregnant does not affect MS.

In terms of causation, 193 (51.5\%) knew that infection and genetic factors seem to be the most crucial cause, but the majority of participants, 240 (51.3\%) did not know the actual cause of the disease. In addition, 97 (20.7\%) of the total participants knew that MS does not transmit from parents to their children, while 131 (28.0\%) believed that it is possible. The fact that being a relative to a MS patient increases the risk by $5 \%$ relative to the general population was known by 82 (17.5\%) of the participants.

Considering diagnostic methods and procedures, 83 $(17.7 \%)$ knew that there is no specific test that can diagnose the disease accurately. Only 33 (7.1\%) knew that intravenous injection with gadolinium reveals new lesions, and 230 (45.5\%) confirmed that MRI is a common method to diagnose MS; 104 (22.2\%) believed that MRI reveals both old and recent lesions. As many as 199 (42.5\%) were aware that repeated MRI leads to better disease monitoring, and 125 (26.9\%) knew that definite MS diagnosis requires a repetition of MRI. With regard to lumber puncture, 150 (32.1\%) recognized the lumbar puncture sample to show an immunological reaction, while 313 (66.9\%) do not know. In terms of the diagnosis, 105 (22.4\%) believed that lumbar puncture is an excellent way to follow the progression of the disease when applied at different occasions, but only 24 (5.1\%) agreed that it is the wrong way to follow the condition.

Regarding the types and treatment, 112 (23.9) knew that "relapsing-remitting" MS is described as repeated attacks at more or less frequent intervals. Of the total participants, 105 (22.4\%) answered that benign MS is characterized by minimal deterioration in function 15 to 20 years after the disease. A total of 191 (40.8\%) stated that there is no cure for MS. In comparison, 46 (9.8\%) believed that there is a cure for MS. Disease-modifying drugs are effective in "relapsing-remitting," but only 19 (4.1\%) knew that, and the majority $(n=341 ; 72.9 \%)$ did not know the answer (-Table 2).

\section{Discussion}

The average MSKQ score among all the participants was $7.42 \pm 4.57$ out of the 25 questions, which is below the average. This result shows an extremely low level of knowl- edge in relation to MS among the subjects, which is shocking since the western region has the highest cases of MS in SA. The low knowledge level can be explained by the fact that the signs of MS are usually invisible and thus many people may not understand the disease. Some cultural beliefs can cause MS patients to hide their illness from others as they feel isolated; thus, fewer people know about the disease. Our result is comparable with other local studies done in Riyadh and Taif, assessing the awareness toward MS among the public, which also shows that the general knowledge is poor. ${ }^{1,13}$ Although the two studies used different assessment tools from ours, the results were similar. The similarities between those studies are based on the study population, as the participants have similar sociocultural factors.

We found that people who were diagnosed with MS have a higher mean score compared with healthy individuals. Knowing that MS patients have higher knowledge than the public is a good indicator of how they understand their illness which leads to better prognosis of the disease. The average score for people with MS in our study is very close to other local and French studies that assess MS knowledge among MS patients. ${ }^{16,20}$ The similarities between the studies are because patients usually have the same basic information about the disease and receive their knowledge from their doctors. Therefore, they will have similar scores on the questionnaires.

We also found that there is no significant relation in knowledge between gender and age. However, as expected, there is a significant relationship between educational level and knowledge score. This shows that there is no specific distribution of the knowledge level among age group or gender; therefore, when conducting an educational campaign, one should assess the entire population from both genders and across all age groups. These results are compatible with a local study in Taif. ${ }^{13}$ Taif is also in the western region as Jeddah, and therefore people there have similar backgrounds and can have similar information regarding the disease.

Most subjects have poor knowledge regarding the etiology, genetics, and treatment of MS, which is a sign of concern. However, most participants possess adequate knowledge of the disease basics in terms of the organ that is affected, and the fact that it is not contagious. This insight can direct educational efforts. Our results are similar to a Saudi study done to evaluate MS patient knowledge. ${ }^{16}$ Although our study assessed MS knowledge among the public, it is still similar to a study that assessed MS patient knowledge. This 
shows that the cause, genetics, and treatment of the disease are usually neglected topics and require more outreach among both the general public and patients.

Public knowledge about the disease is not only important for the early detection of the disease but also helps increase quality of life for patients. With poor knowledge, it is difficult to treat and communicate with patients which, in turn, can negatively affect their mental and physical health. We need further education about the disease to support people with MS and reduce the burden of the disease. ${ }^{17}$

\section{Conclusion}

In this study, we found that the mean knowledge score was below the average, which implies very poor knowledge among the community. People are still unfamiliar with the disease, although the Western region has the highest cases of MS in the country. Patients with MS face mental, financial, and physical challenges throughout their lives. Therefore, the community needs to have a high knowledge level to help remove the stigma about their disease and improve their quality of life. Thus, increasing public knowledge in relation to the disease is essential. This can be done by conducting educational programs and campaigns through various media.

\section{Limitations}

Several limitations should be addressed. First, the sample size was small, which might not be generalized to the total community. Second, there was no equal distribution between males and females-there were twice as many women. Third, the study used convivence sampling, which is subjected to numerous biases. Fourth, the study collected data using an electronic sheet, which might let some subjects search for answers on the Internet. Fifth, the questionnaire does not assess knowledge regarding the symptoms and complications of the disease.

\section{Funding}

None.

\section{Conflict of Interest \\ None declared.}

\section{References}

1 Hudaif HSA, Bwardi NA, Kojan S. Assessment of multiple sclerosis awareness and knowledge among the Saudi population in Riyadh City. Mult Scler Relat Disord 2014;3(06):758

2 Mohammed EMA. Multiple sclerosis is prominent in the Gulf states. Pathogenesis 2016;3(02):19-38
3 Lassmann H, Brück W, Lucchinetti CF. The immunopathology of multiple sclerosis: an overview. Brain Pathol 2007;17(02): 210-218

4 Wallin MT, Culpepper WJ, Nichols E, et al; GBD 2016 Multiple Sclerosis Collaborators. Global, regional, and national burden of multiple sclerosis 1990-2016: a systematic analysis for the Global Burden of Disease Study 2016. Lancet Neurol 2019;18(03): 269-285

5 Pugliatti M, Rosati G, Carton H, et al. The epidemiology of multiple sclerosis in Europe. Eur J Neurol 2006;13(07):700-722

6 Koch-Henriksen N, Sørensen PS. The changing demographic pattern of multiple sclerosis epidemiology. Lancet Neurol 2010; 9(05):520-532

7 Evans C, Beland S-G, Kulaga S, et al. Incidence and prevalence of multiple sclerosis in the Americas: a systematic review. Neuroepidemiology 2013;40(03):195-210

8 Yadav V, Shinto L, Bourdette D. Complementary and alternative medicine for the treatment of multiple sclerosis. Expert Rev Clin Immunol 2010;6(03):381-395

9 Organization WH, Federation MSI. Atlas: multiple sclerosis resources in the world. 2008. Accessed July 12, 2021 at: https:// apps.who.int/iris/handle/10665/43968

10 Browne P, Chandraratna D, Angood C, et al. Atlas of multiple sclerosis 2013: agrowing global problem with widespread inequity. Neurology 2014;83(11):1022-1024

11 Al Wutayd O, Mohamed AG, Saeedi J, Al Otaibi H, Al Jumah M. Environmental exposures and the risk of multiple sclerosis in Saudi Arabia. BMC Neurol 2018;18(01):86

12 Barcellos LF, Thomson G. Genetic analysis of multiple sclerosis in Europeans. J Neuroimmunol 2003;143(1-2):1-6

13 Amer M, AlZahrani W, AlZahrani A, et al. Assessment of multiple sclerosis awareness: knowledge and attitude among Saudi population in Taif City, Ksa. Int J Adv Res (Indore) 2016;4(12): 1758-1766

14 Kabay SC, Karaman HO, Ayas S, Mestan E, Cetiner M. Knowledge and attitude towards multiple sclerosis in Turkey. Published online 2014. Available at: https://journals.sagepub.com/doi/ $10.1177 / 1352458514546077$

15 Abbasi V, Tabrizian S, Atalu A, Aslanian R, Zakeri A. Knowledge of pregnant women towards multiple sclerosis. Int J Community Med Public Health 2018;5(12):5025

16 Abulaban A, Altowairqi A, Altowairqi H, et al. Multiple sclerosis patients knowledge in Saudi Arabia. Neurosciences (Riyadh) 2019;24(04):327-330

17 AlJumah M, Bunyan R, Al Otaibi $\mathrm{H}$, et al. Rising prevalence of multiple sclerosis in Saudi Arabia, a descriptive study. BMC Neurol 2020;20(01):49

18 Sample Size Calculator by Raosoft, Inc. Accessed June 30, 2020 at: http://www.raosoft.com/samplesize.html

19 Giordano A, Uccelli MM, Pucci E, et al; SIMS-Trial group. The Multiple Sclerosis Knowledge Questionnaire: a self-administered instrument for recently diagnosed patients. Mult Scler 2010;16 (01):100-111

20 Abolfazli R, Elyasi A, Javadi MR, et al. Knowledge and attitude assessment of Iranian multiple sclerosis patients receiving interferon beta. Iran J Neurol 2014;13(03):160-167 